\title{
Spectroscopic, Morphological, and Mechanistic Investigation of the Solvent- Promoted Aggregation of Porphyrins Modified in meso-Positions by Glucosylated Steroids
}

\author{
Karel Zelenka, ${ }^{[a]}$ Tomáš Trnka, ${ }^{[a]}$ Iva Tišlerová, ${ }^{[a]}$ Donato Monti, ${ }^{*[c]}$ Stefano Cinti, ${ }^{[c]}$ \\ Mario Luigi Naitana, ${ }^{[c]}$ Luca Schiaffino, ${ }^{[c]}$ Mariano Venanzi, ${ }^{[c]}$ Giuseppe Laguzzi, ${ }^{[d]}$ \\ Loredana Luvidi, ${ }^{[d]}$ Giovanna Mancini, ${ }^{[d]}$ Zdena Nováková, ${ }^{[b]}$ Ondřej Šimák, ${ }^{[b]}$ \\ Zdeněk Wimmer, ${ }^{[\mathrm{e}]}$ and Pavel Drašar*[b]
}

\begin{abstract}
Solvent-driven aggregation of a series of porphyrin derivatives was studied by UV/Vis and circular dichroism spectroscopy. The porphyrins are characterised by the presence in the meso positions of steroidal moieties further conjugated with glucosyl groups. The presence of these groups makes the investigated macrocycles amphiphilic and soluble in aqueous solvent, namely, dimethyl acetamide/ water. Aggregation of the macrocycles is triggered by a change in bulk solvent composition leading to formation of large architectures that express supramolecular chirality, steered by the presence of the stereogenic centres on the periphery of the macrocycles. The aggregation behaviour and chiroptical
\end{abstract}

features of the aggregates are strongly dependent on the number of moieties decorating the periphery of the porphyrin framework. In particular, experimental evidence indicates that the structure of the steroid linker dictates the overall chirality of the supramolecular architectures. Moreover, the porphyrin concentration strongly affects the aggregation mechanism and the CD intensities of the spectra. Notably, AFM investigations reveal strong differences in aggregate morphology that are dependent on the nature of the ap-

Keywords: aggregation • chirality • porphyrinoids • steroids • supramolecular chemistry pended functional groups, and closely in line with the changes in aggregation mechanism. The suprastructures formed at lower concentration show a network of long fibrous structures spanning over tens of micrometres, whereas the aggregates formed at higher concentration have smaller rodshaped structures that can be recognised as the result of coalescence of smaller globular structures. The fully steroid substituted derivative forms globular structures over the whole concentration range explored. Finally, a rationale for the aggregation phenomena was given by semiempirical calculations at the PM6 level.

\section{Introduction}

[a] Dr. K. Zelenka, Prof. Dr. T. Trnka, Dr. I. Tišlerová Charles University, Department of Organic Chemistry Albertov 8, 12840 Prague 2 (Czech Republic)

[b] Z. Nováková, Dr. O. Šimák, Prof. Dr. P. Drašar Department of Natural Compounds Chemistry Institute of Chemical Technology Prague Technická 5, 16628 Prague 6 (Czech Republic) Fax: $(+420) 220-443-422$

[c] Dr. D. Monti, Dr. S. Cinti, Dr. M. L. Naitana, Dr. L. Schiaffino, Prof. Dr. M. Venanzi

University of Rome Tor Vergata

Department of Chemical Technologies

Via della Ricerca Scientifica 1, 00133, Rome (Italy)

Fax: (+30) 0672594328

E-mail:monti@stc.uniroma2.it

[d] Dr. G. Laguzzi, Dr. L. Luvidi, Dr. G. Mancini

IMR-CNR, c/o Department of Chemistry, University of Rome La Sapienza, P.le A. Moro 5, 00185, Rome (Italy)

[e] Prof. Dr. Z. Wimmer

Institute of Experimental Botany AS CR vvi, Isotope Laboratory Vídeňská 1083, 14220 Prague 4 (Czech Republic)

Supporting information for this article is available on the WWW under http://dx.doi.org/10.1002/chem.201101163.
The supramolecular chirality of porphyrin derivatives is an important aspect of these macrocycles, in which chiral (or even achiral) building blocks assemble and organise themselves into chiral architectures through a combination of noncovalent interactions. ${ }^{[1]}$ This is usually accomplished by a number of well-established procedures: 1) templated aggregation on chiral natural and non-natural polymer matrices, ${ }^{[2]}$ 2) chiral-ligand coordination, ${ }^{[3]} 3$ ) spontaneous symmetry breaking induced by stirring, ${ }^{[4]}$ ) electrostatic interactions, ${ }^{[5]}$ 5 ) by Langmuir-Blodgett and Langmuir-Schäfer techniques, ${ }^{[6]}$ and, as recently reported, 6) by interaction with chiral surfactants. ${ }^{[7]}$

Our contribution to this field concerns functionalisation of the periphery of a porphyrin macrocycle by a chiral moiety, namely, a configurationally stable amino acid residue ${ }^{[8]}$ a robust $\mathrm{C}$-glycosidic group, or a steroid moiety. ${ }^{[9]}$ These groups, besides imparting an amphiphilic character to the molecular frameworks, steer solvent-promoted self-aggregation toward formation of supramolecular structures 
with a high degree of asymmetry. The strong dependence of the resulting chiroptical features on bulk solvent properties such as the water content, ionic strength, and so on, indicates the occurrence of a subtle balance of forces during the molecular recognition processes. Moreover, we recently reported that simply changing one stereogenic centre in $C$-glycoside derivatives, from " $C$-D-gluco" to " $C$-D-galacto" configuration, results in a change of sign of the CD spectra, ${ }^{[9 b]}$ indicating an opposite mutual configuration of the chromophores.

Hence, we decided to study the aggregation properties of porphyrin derivatives, decorated with peripheral glucosylated steroid derivatives. This functionalisation offers the opportunity to exploit the combined effects of the glucosylated steroid moieties in conjunction with the porphyrin aromatic platform. In this particular field, little work has been done so far. Studies on the photophysical properties of porphyrin-fullerene hybrids linked by a steroid moiety were reported. ${ }^{[11 a]}$ Moreover, porphyrin-steroid conjugates are studied for comprehension of the processes involved in artificial antenna systems. ${ }^{[11 \mathrm{~b}]}$ The catalytic properties of some oestrogen-porphyrin conjugates were reported, ${ }^{[12]}$ and a steroidporphyrin conjugate was intended for saccharide sensing in protic media. ${ }^{[13]} \mathrm{An} \mathrm{Mn}^{\mathrm{III}}$ porphyrin-steroid conjugate was used as a semi-synthetic antibody. ${ }^{[14]}$ A review on dimeric and oligomeric steroids highlights some supramolecular applications of the conjugation of steroids and porphyrins, ${ }^{[15]}$ and membrane-spanning porphyrins ${ }^{[16]}$ have been employed as mimics of cytochrome P450. Furthermore, some steroidcapped porphyrins have been reported to show interesting behaviour as molecular bowls. ${ }^{[17]}$

The aggregation properties of the title systems were studied in aqueous solvent mixtures by several spectroscopic and kinetic means, to give insight into the mechanism of assembly, and on the nature of the resulting supramolecular architectures. This can be important in the field of molecular materials, and for sensor applications, owing to the complexity of the molecular frameworks, which offer a variety of interaction sites for molecular recognition and discrimination of complex matrices of analytes. ${ }^{[18]}$ Moreover, as recently reported for related structures, these sugar-conjugated porphyrins could be of importance in the photodynamic therapy (PDT) of tumours. In this regard, the affinity of the photosensitiser to the cell surface of neoplastic tissues is enhanced by the presence of sugar moieties, and the further transport into tissue is effectively modulated by the amphiphilicity of the drug. ${ }^{[19]}$

\section{Results and Discussion}

We used our previously reported procedures ${ }^{[20]}$ to prepare 5,10,15,20-tetrakis[3 $\alpha$-(2,3,4,6-tetra- $O$-benzyl- $\beta$-D-glucopyranosyloxy)-5 $\beta$-24-norcholan-23-yl]porphyrin (H2TGS-P) and 5,15-bis(pentafluorophenyl)-10,20-bis[3 $\alpha$-(2,3,4,6-tetra- $O$ benzyl- $\beta$-D-glucopyranosyloxy))-5 $\beta$-24-norcholan-23-yl]porphyrin ( $\mathbf{H}_{2}$ DGS-P). The derivatives are characterised by the presence of two (trans- $\mathrm{A}_{2} \mathrm{~B}_{2}$ type) or four glucosylated steroid ( $\mathrm{A}_{4}$ type) in the meso position $\left(\mathbf{H}_{2}\right.$ DGS-P and $\mathbf{H}_{2}$ TGS$\mathbf{P}$, respectively).
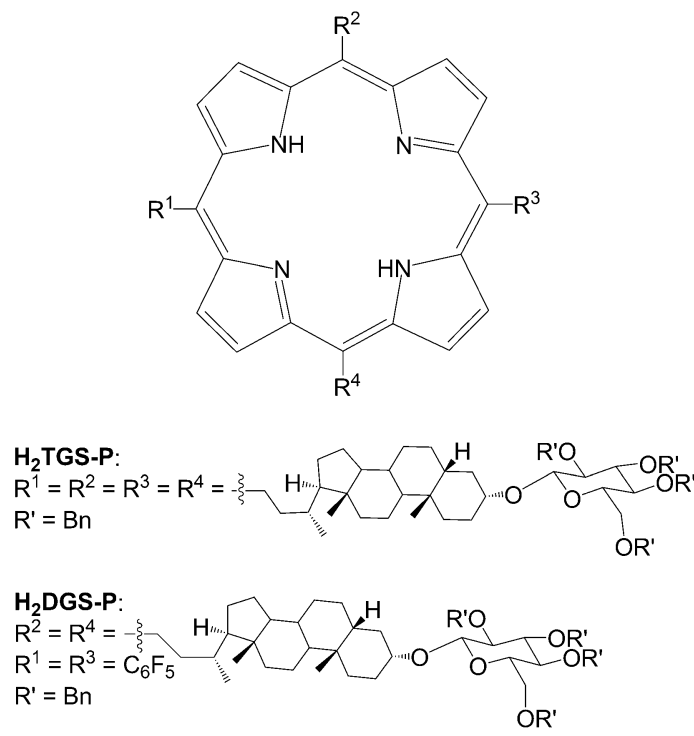

Aggregation studies: The aggregation behaviour of porphyrin derivatives was studied in aqueous solvent mixtures such as dimethylacetamide (DMAc)/water in various proportions. Such solvent combinations have been found to give the best performances in terms of solubility, stability of the porphyrin solutes, and reproducibility of the results, with respect to other investigated hydro-organic media such as ethanol/ water, acetonitrile/water, and tetrahydrofuran/water (results not reported).

In pure DMAc, $\mathbf{H}_{2}$ TGS-P shows a sharp Soret Band at $418 \mathrm{~nm}$, indicating that the macrocycle is present in solution in monomeric form. Analogously, bis-pentafluorophenyl derivative $\mathbf{H}_{2}$ DGS-P features a sharp Soret band, hypsochromically shifted at $413 \mathrm{~nm}$, due to the presence of strongly electron withdrawing fluorinated groups. In mixed solvent media, an increasing fraction of water triggers aggregation of the monomers with formation of supramolecular structures, as indicated by the typical spectroscopic UV/Vis changes (hypochromicity, band broadening, and wavelength shift; Figure 1). The solvent composition at which onset of aggregation occurs, as well as its extent at equilibrium, depends on the intimate nature of the groups decorating the molecular frameworks. Detailed kinetic studies on the effect of substrate concentration, and solvent properties, will be reported and discussed below.

In the case of $\mathbf{H}_{2}$ TGS-P, bearing four steroid groups $\left(\mathrm{A}_{4}\right.$ type), aggregation is complete with $20 \%$ of water, whereas for the disubstituted trans- $\mathrm{A}_{2} \mathrm{~B}_{2}$ congener $\mathbf{H}_{2}$ DGS-P, having two pentafluorophenyl groups, complete aggregation requires a larger fraction of water $(40 \%)$. This can certainly be ascribed to the effect of the overall polarity of the compounds, and on the specific interactions of the substituent groups with the solvent molecules, which are more favourable for the more polar pentafluorophenyl moieties. 

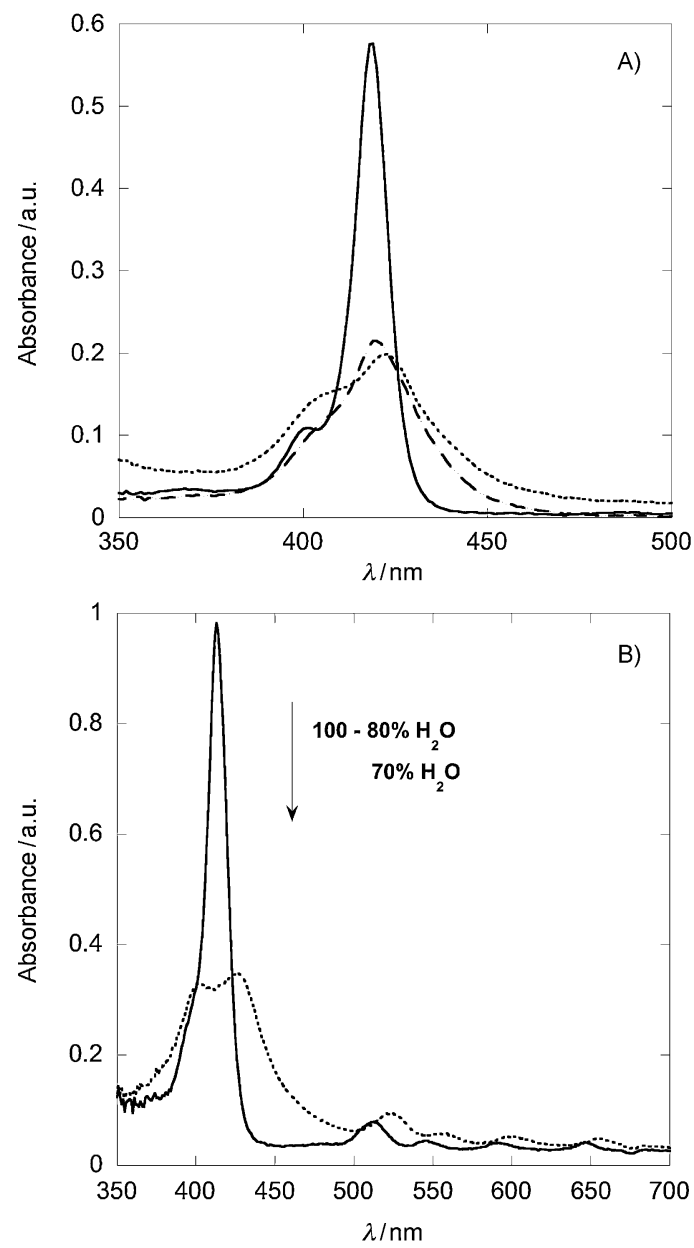

Figure 1. UV/Vis spectra of porphyrin derivatives in aqueous solvent mixtures. A) H2TGS-P, —: $100 \%$ DMAc, -.--: $90 \%$ DMAc, …..: $80 \%$ DMAc. B) H2DGS-P, — : $100-80 \%$ DMAc, …..: $60 \%$ DMAc.

The differences in the self-assembly propensity are also clearly reflected in the spectral patterns of the final aggregated species (Figure 1). In the case of $\mathbf{H}_{2}$ TGS-P at $2.7 \mu \mathrm{M}$ aggregation results in the formation of scarcely red-shifted J-type bands in the UV/Vis spectra, whereas at higher concentration (ca. $3 \mu \mathrm{M}$ ) the aggregation process give rise to mixed J- and H-type morphologies, in accordance with the presence of an additional blue-shifted feature at $405 \mathrm{~nm}$. Similar behaviour was found in aggregation studies on similar tetra-meso-glucoporphyrin derivatives carried out in aqueous acetonitrile. ${ }^{[9]}$ Conversely, in the case of the less crowded disubstituted $\mathbf{H}_{2}$ DGS-P aggregation gives species characterised by excitonically coupled Soret B bands, with the "spectroscopic barycentre" remaining fixed at $413 \mathrm{~nm}$.

Concomitant fluorescence spectroscopic studies reveal that in both cases aggregation occurs with quenching and red shift of the fluorescence emission at the same solvent composition as indicated by UV/Vis spectroscopy (results not shown). Notably, the shift of emission maxima is higher for aggregates of $\mathbf{H}_{2}$ TGS-P $\left(\lambda_{\max }=660 \mathrm{~nm}\right)$ than for congener H$_{2}$ DGS-P $\left(\lambda_{\max }=645 \mathrm{~nm}\right)$. This again strictly parallels the behaviour featured in the UV/Vis spectral patterns.
These findings are further corroborated by resonance light scattering spectroscopy (RLS) measurements, which show strong features upon aggregation, indicating the formation of large structures formed by a number of monomers in electronic communication higher than 25. ${ }^{[21]}$

Circular dichroism spectroscopic studies showed that in all cases the interaction results in formation of chiral supramolecular species, but with remarkably strong differences in terms of band intensity and shape, depending on the kind and degree of substitution of the ring periphery. This finding strongly suggests different modes of molecular interaction between the different macrocycles, as a consequence of the structural diversity. The CD spectrum of $\mathbf{H}_{2}$ TGS-P (ca. $1 \mu \mathrm{M})$ in pure DMAc features a weak dichroic negative band at $419 \mathrm{~nm}$ (Figure 2A), which can be safely interpreted on the basis of the induction effect of the bulky chiral substituent on the electronic transition dipoles (Soret B band), ${ }^{[22]}$ and on the effect of distortion of the porphyrin framework from planarity. The "intramolecular" nature of this effect could be proven by the fact that also in the presence of added salts (i.e., $1.5 \mathrm{~m} \mathrm{NaBr}$ ) the induced $\mathrm{CD}$ (ICD) intensi-
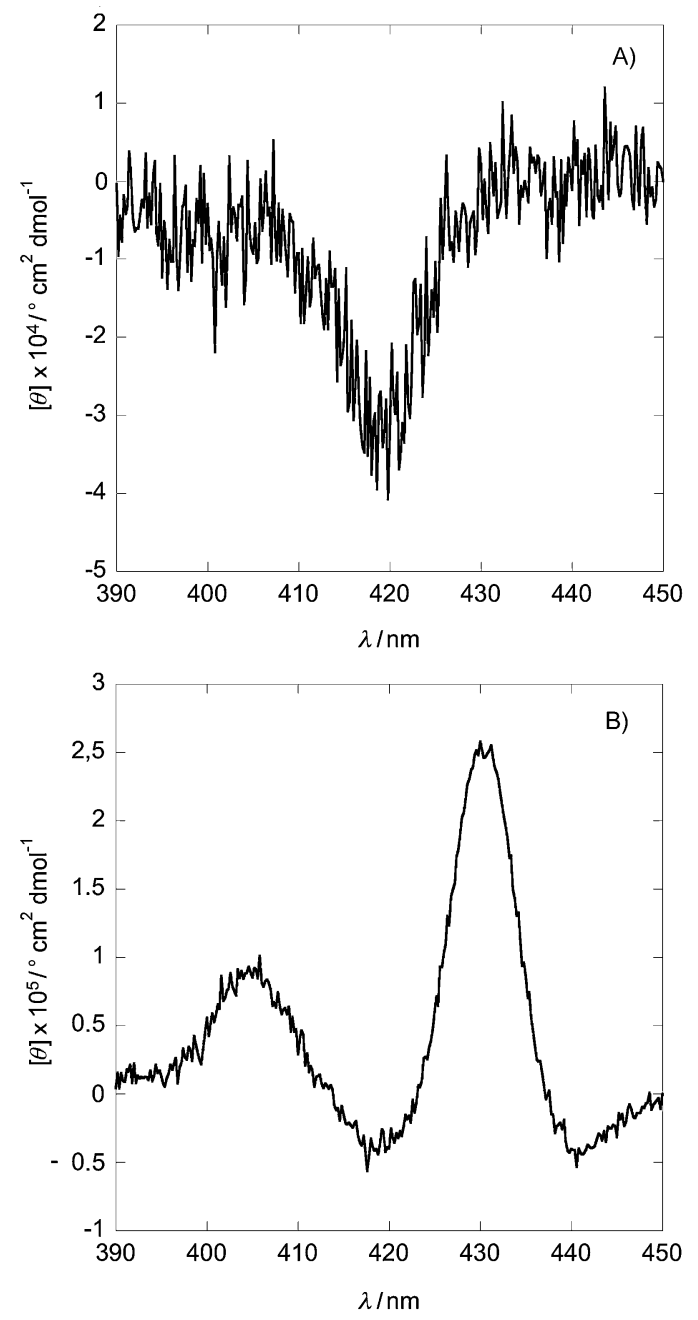

Figure 2. CD spectra of $2.5 \times 10^{-6} \mathrm{M}$ H2TGS-P in A) DMAc and B) DMAc/water $(80: 20)$. 
ty remains unchanged, ruling out, at this stage, the effect of porphyrin aggregation, which should otherwise be influenced by ionic strength. The same considerations hold for the other derivatives studied (see below). When the studies are carried out under aggregative conditions (i.e., > $30 \%$ water, see Experimental Section), only very weak CD features are detected, which are scarcely distinguishable from the background noise, and indicate mainly formation of structures with aspecific, weakly chirally active morphology. Interestingly, some more evident $\mathrm{CD}$ features become appreciable at higher porphyrin concentration. In this case both higher-energy and lower-energy, partially superposed, bisignated negative bands are observed, indicating formation of chiral species of either H-like or J-like character, as formerly shown by UV/Vis spectroscopy (Figure 2B). ${ }^{[23]}$

The CD spectrum of $\mathbf{H}_{2}$ DGS-P in pure DMAc (Figure 3) features an ICD band due to electronic interaction of the steroid moieties with the tetrapyrrolic platform. Significantly, in this case solvent-driven aggregation occurs with the formation of strongly $\mathrm{CD}$ active species, with intense nega-
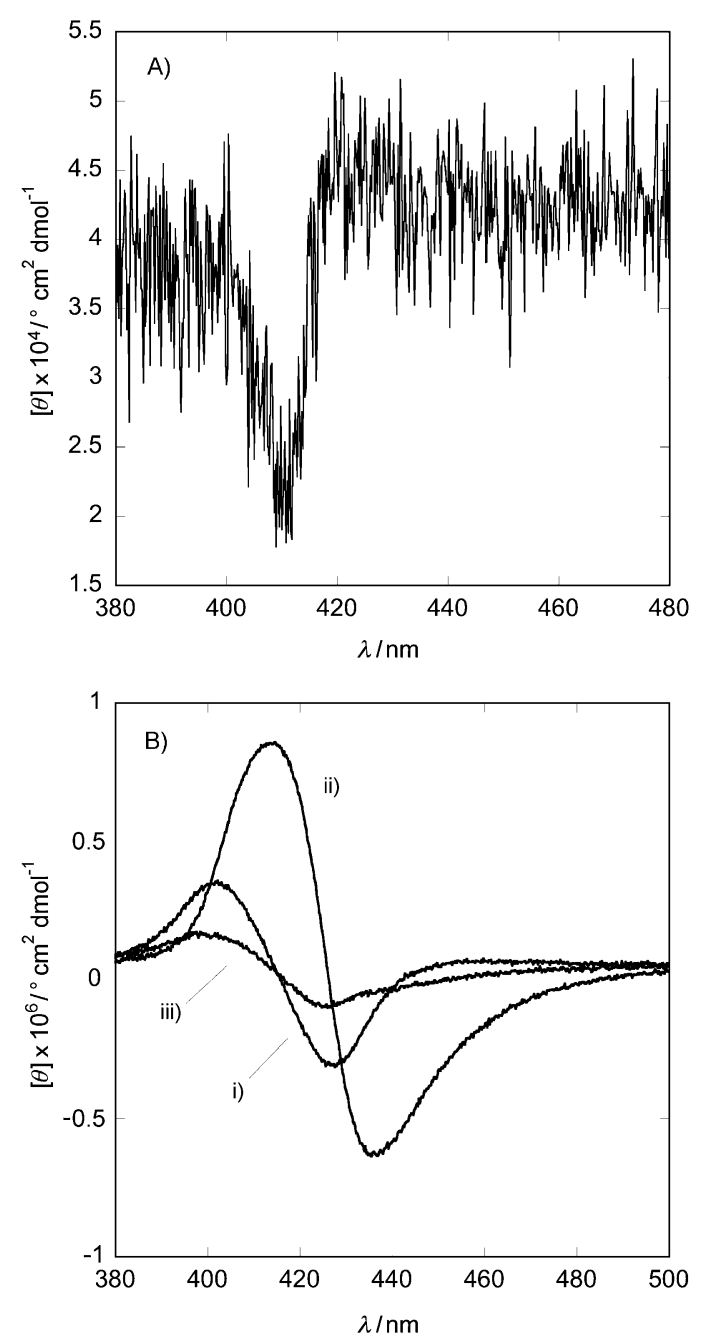

Figure 3. CD spectra of $\mathbf{H}_{2}$ DGS-P $(1.6 \mu \mathrm{M})$ in different media. A) DMAc. B) DMAc/ $\mathrm{H}_{2} \mathrm{O}$ : i) $80 \%$ DMAc, ii) $40 \%$ DMAc, iii) $0 \%$ DMAc. tive bisignated Cotton effect, as a consequence of strong electronic coupling between the macrocycles. ${ }^{[3 \mathrm{~d}, 24,25]}$ The negative sign of the spectral patterns is suggestive of a mutual anticlockwise arrangement of the tetrapyrrolic platforms on forming the aggregate suprastructures. ${ }^{[26]}$ Here, too, good analogies between the results of different spectroscopic techniques are found, as the maximum CD effect is reached at about $40 \%$ water content (Figure 3B), where aggregation is virtually complete, as already indicated by UV/ Vis spectroscopy. On the other hand, aggregates formed in nearly pure water show lower CD intensities, indicating formation of less-ordered structures. This is due to the increased aggregation rate, as already observed by our group in the case of related chiral porphyrin derivatives. ${ }^{\left[{ }^{[c]}\right]}$

The large differences in $\mathrm{CD}$ intensity observed for $H_{2}$ TGS-P and $H_{2}$ DGS-P should be the consequence of either the steric hindrance caused by the bulky moieties being smaller in the trans- $\mathrm{A}_{2} \mathrm{~B}_{2}$ frame, so that tighter interaction between the aromatic platforms is possible, or the dynamics of the sugar residues, which may hamper tighter interaction. It is noteworthy that the CD spectra of these compounds feature bands of opposite sign to that formerly observed for simpler glycosylated porphyrin derivatives lacking steroid spacers. ${ }^{[\mathrm{b}]}$ This can interpreted on the basis of the formation of chiral suprastructures, whose mutual spatial configuration is governed by the molecular information introduced by the rigid steroid structures.

Kinetic studies: Kinetic studies on the aggregation of porphyrin derivatives $\mathbf{H}_{2}$ TGS-P and $\mathbf{H}_{2}$ DGS-P were performed to shed light on the effect of the molecular structure on the aggregation mechanism. The studies on $\mathbf{H}_{2}$ DGS-P were performed in DMAc/water (87:13), as precisely this solvent composition allowed for optimal reaction rates for convenient monitoring by conventional spectroscopic means. ${ }^{[27]}$ All reactions showed a clean isosbestic point at $426 \mathrm{~nm}$ indicating formation of aggregates with structurally similar morphology. A close analysis of the kinetic behaviour showed remarkable dependence of the self-assembly process on the reaction conditions. The aggregation properties, in terms of constant rates and mechanism, are strongly influenced by the starting porphyrin concentration. Aggregation at low concentration (i.e., $0.8 \mu \mathrm{M}$ ) showed a typical sigmoidal decay indicative of a peculiar autocatalytic behaviour and likely formation of fractal-type species (Figure 4A). The decay could be conveniently fitted with the following "unconventional" equation, developed by Pasternack and co-workers [Eq. (1) $]^{[28]}$

$$
\begin{aligned}
&\left(\mathrm{Ext}_{t}-\mathrm{Ext}_{\infty}\right) /\left(\mathrm{Ext}_{0}-\mathrm{Ext}_{\infty}\right)= \\
& {[1+(m-1)]\left[k_{0} t+(n+1)^{-1}\left(k_{\mathrm{c}} t\right)^{n+1}\right]^{1 /(m-1)} }
\end{aligned}
$$

where $\mathrm{Ext}_{0}, \mathrm{Ext}_{\infty}$ and $\mathrm{Ext}_{t}$ are the extinctions at initial, final and time $t$, respectively, ${ }^{[29,30]} k_{0}$ and $k_{\mathrm{c}}$ the "uncatalysed" and "catalysed" reaction rates, $m$ the nucleation factor (i.e., the minimum number of aggregated porphyrin monomers acting 

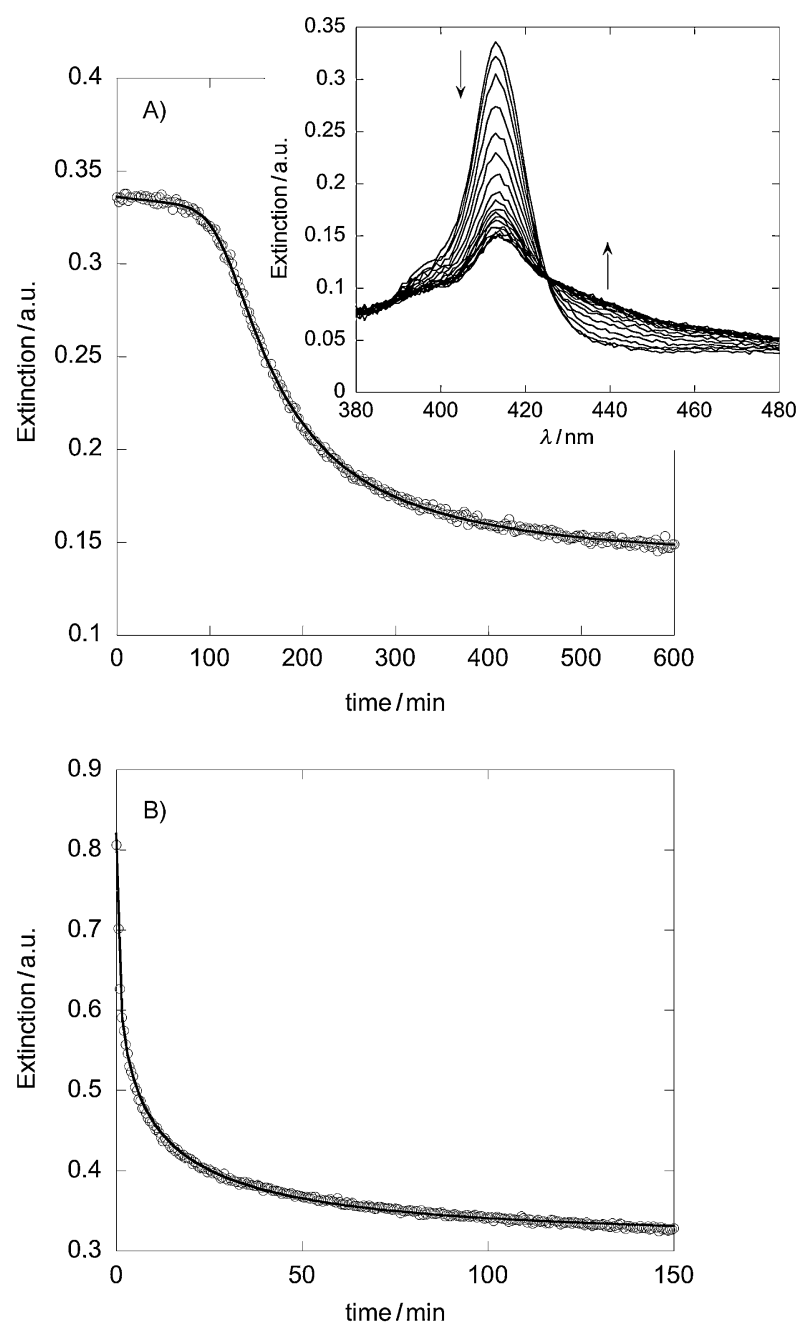

Figure 4. A) Kinetic plot for the aggregation of $\mathbf{H}_{2}$ DGS-P $\left(0.8 \times 10^{-6} \mathrm{M}\right)$ in DMAc $/ \mathrm{H}_{2} \mathrm{O}(87: 13)$ at $298 \mathrm{~K}, \lambda=413 \mathrm{~nm}$. ○: experimental points, theoretical curve fit according to Equation (1). Inset: The corresponding UV/Vis spectral variations. B) Kinetic plot for the reaction carried out at $2.4 \times 10^{-6} \mathrm{M}$. The fit was accomplished according to Equation (2).

as a "nucleation seeds", formed during the first delay period) and $n$ the fractal growth factor. A value of $n>1$ indicates the occurrence of cooperative catalysed aggregate growth. In this equation, contrary to classical kinetic treatment, the "catalysed" rate constant is regarded as time-dependent.

A regression fit according to the proposed model (see Experimental Section for details) gave the parameters $k_{0}=$ $2.9 \times 10^{-4} \mathrm{~s}^{-1}, k_{\mathrm{c}}=9.1 \times 10^{-4} \mathrm{~s}^{-1}$, with mean $m$ value of 5 , and $n \approx 7$. The experiment carried out at intermediate concentration (i.e., $1.6 \mu \mathrm{M}$ ) revealed a progressive profile change, with an evident reduction of the initial "lag phase", that is, induction period.

A least-squares regression fit of the experimental data by means of Equation (1), gave similar values for $k_{0}$, and an increased catalysed rate constant $k_{\mathrm{c}}$ within the experimental error. Moreover, the increased $m$ value and decreased value of the stretching factor $n$ likely indicate gradual biasing toward a mechanism involving formation of larger nucleation seeds $(m \approx 8)$ that grow in a following step characterised by a reduced degree of cooperativity $(n \approx 2-3)$.

Remarkably, by merely further increasing threefold the initial porphyrin concentration (i.e., from 0.8 to $2.4 \mu \mathrm{M}$ ) a kinetic change occurs, toward stretched exponential decay behaviour, indicating the onset of a diffusion-limited aggregation (DLA) mechanism (Figure 4B). The decay can be nicely fitted by Equation (2), which has been commonly employed, for example, in the aggregation of dyes onto charged polymers $^{[31]}$ and in related studies ${ }^{[9]}$

$\mathrm{Ext}_{t}=\mathrm{Ext}_{0}+\left(\mathrm{Ext}_{\infty}-\mathrm{Ext}_{0}\right)\left[1-\exp (-k t)^{n}\right]$

where $k$ is the apparent first-order aggregation rate constant, and $n$ the stretching factor, which modulates the diffusion growth of the aggregates, and for this kind of mechanism is required to be $n<1$. This kinetic behaviour implies the initial rapid formation of small porphyrin clusters (nucleation seeds) subsequently growing by slow inclusion of diffusing porphyrin monomers. Evidently, this latter pathway is biased at high monomer concentration, at which the nucleation phase is no longer the rate-determining step. This is an unprecedented result, with respect to structurally related porphyrin frameworks studied by us, for which constancy of the self-assembly process upon changing the porphyrin concentration within a larger window was commonly observed.

A change of aggregation mechanism, however, has been reported in the literature for highly charged, water-soluble porphyrin platforms in which biasing of the mode of self-interaction is promoted by a large change in the ionic strength of the medium ${ }^{[32]}$ or by a severe variation of the porphyrin concentration. ${ }^{[33]}$ This is accompanied by a change from fractal to nanorod structures of the $\mathrm{J}$ aggregates upon increasing the porphyrin concentration. A change in kinetic profile was also observed on changing the mixing protocol of the reactants in porphyrin aggregation promoted by $\mathrm{HCl}^{[34]}$ In the present case, the change of aggregation mechanism must be due only to the effect of the macrocycle concentration, as the medium composition, preparation of the solutions, and their mixing procedures were kept constant for all of the performed kinetic runs, as reported in detail in the Experimental Section.

Concomitant CD studies gave further insights. The kinetic behaviour closely follows that observed by UV/Vis spectroscopy for the aggregation of $0.8 \mu \mathrm{M} \mathbf{H}_{2}$ DGS-P (Figure 5). The same mathematical treatment [Eq. (1)] gave results that were in good agreement with those obtained by UV/Vis spectroscopy (Table 1).

The final ellipticity of the $\mathrm{CD}$ bands strongly depends on porphyrin concentration. The maximum $\theta$ values increase by one order of magnitude, from $3.5 \times 10^{5}$ to $3.1 \times$ $10^{6 \circ} \mathrm{cm}^{2} \mathrm{dmol}^{-1}$, on going from 0.8 to $1.6 \mu \mathrm{M}$, respectively (Figure 6). On further increasing the concentration a strong decrease in $\mathrm{CD}$ intensity, by about one order of magnitude, occurs $\left(6 \times 10^{5 \circ} \mathrm{cm}^{2} \mathrm{dmol}^{-1}\right.$ at $\left.2.4 \mu \mathrm{M}\right)$. This effect should be the consequence of the observed change in mechanism, 

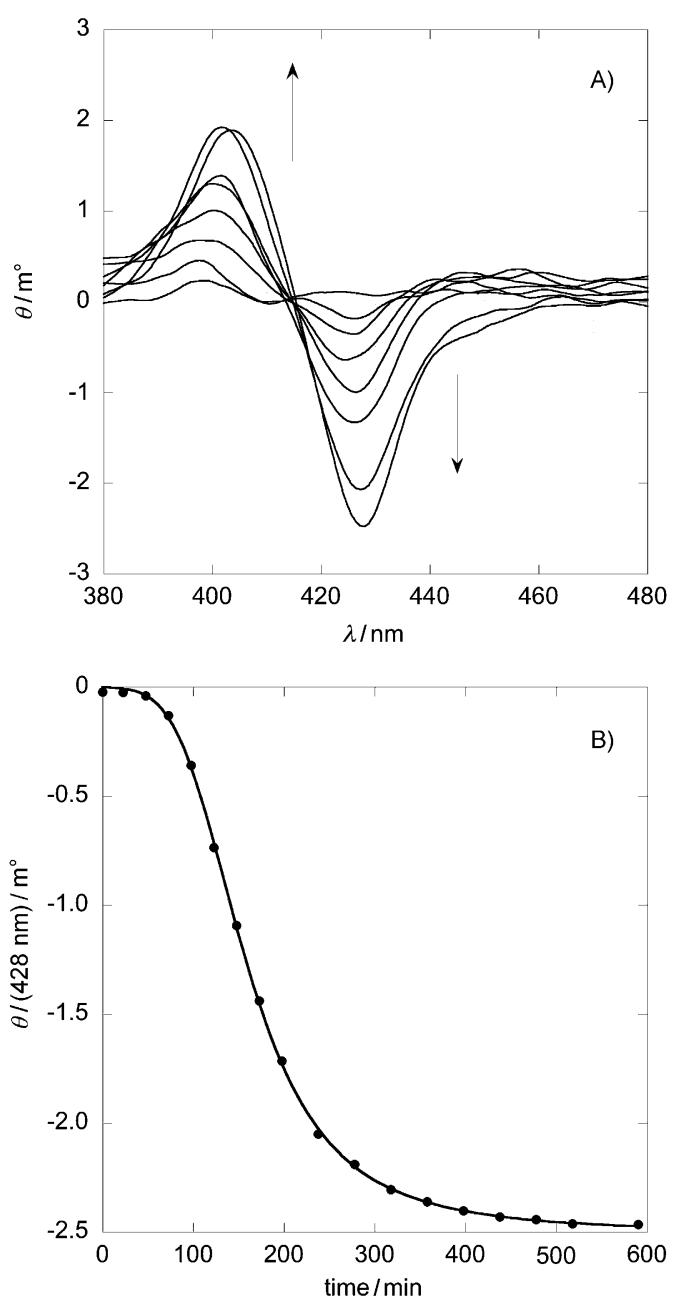

Figure 5. A) CD spectral variation with time of $\mathbf{H}_{2}$ DGS-P in DMA/water $(87: 13)$ at $0.8 \mu \mathrm{M}$ and $298 \mathrm{~K}$. B) Corresponding kinetic plot at $\lambda=428 \mathrm{~nm}$.

Table 1. Kinetic parameters for the aggregation of $\mathbf{H}_{2}$ DGS-P ${ }^{[\mathrm{a}]}$

\begin{tabular}{llclc}
\hline$\left[\mathrm{H}_{2} \mathrm{DGS}-\mathrm{P}\right][\mu \mathrm{M}]$ & $10^{4} k_{0}\left[\mathrm{~s}^{-1}\right]$ & $10^{4} k_{\mathrm{c}}\left[\mathrm{s}^{-1}\right]$ & $m$ & $n$ \\
\hline 0.80 & $2.9 \pm 0.3$ & $9.07 \pm 0.03$ & $5.1 \pm 0.4$ & $6.6 \pm 0.1$ \\
1.60 & $3.5 \pm 0.4$ & $15.70 \pm 0.05$ & $7.6 \pm 0.3$ & $2.5 \pm 0.2$ \\
$1.60^{[\mathrm{b}]}$ & $3.3 \pm 0.6$ & $13.12 \pm 0.06$ & $8.1 \pm 0.1$ & $2.8 \pm 0.1$ \\
$1.60^{[\mathrm{c}]}$ & $4.5 \pm 0.5$ & $15.1 \pm 0.2$ & $9.7 \pm 0.6$ & $3.1 \pm 0.3$ \\
$2.40^{[\mathrm{d}]}$ & & $38.0 \pm 0.1$ & & $0.40 \pm 0.05$
\end{tabular}

[a] Kinetic runs in DMAc/ $\mathrm{H}_{2} \mathrm{O}(87: 13)$ at $298 \mathrm{~K}$ monitored by UV/Vis spectroscopy at $\lambda=413 \mathrm{~nm}$ according to Equation (1). [b] Monitored by CD spectroscopy at $\lambda=428 \mathrm{~nm}$. [c] Monitored by fluorescence spectroscopy at $\lambda=413 \mathrm{~nm}$. [d] Monitored by UV/Vis spectroscopy at $\lambda=413 \mathrm{~nm}$. Kinetic decay fitted by Equation (2).

which leads to the formation of supramolecular structures with different intimate morphologies. Nevertheless, the CD signs of the spectra remained unchanged throughout the changes in concentration, and this indicates constancy of the mutual porphyrin configuration. ${ }^{[26]}$

Analogous kinetic experiments were carried out on $\mathbf{H}_{2}$ TGS-P. The results are summarised in Table 2. The runs were performed in DMAc/water (91/9). Despite the lower polarity of the medium, the overall self-assembly process is

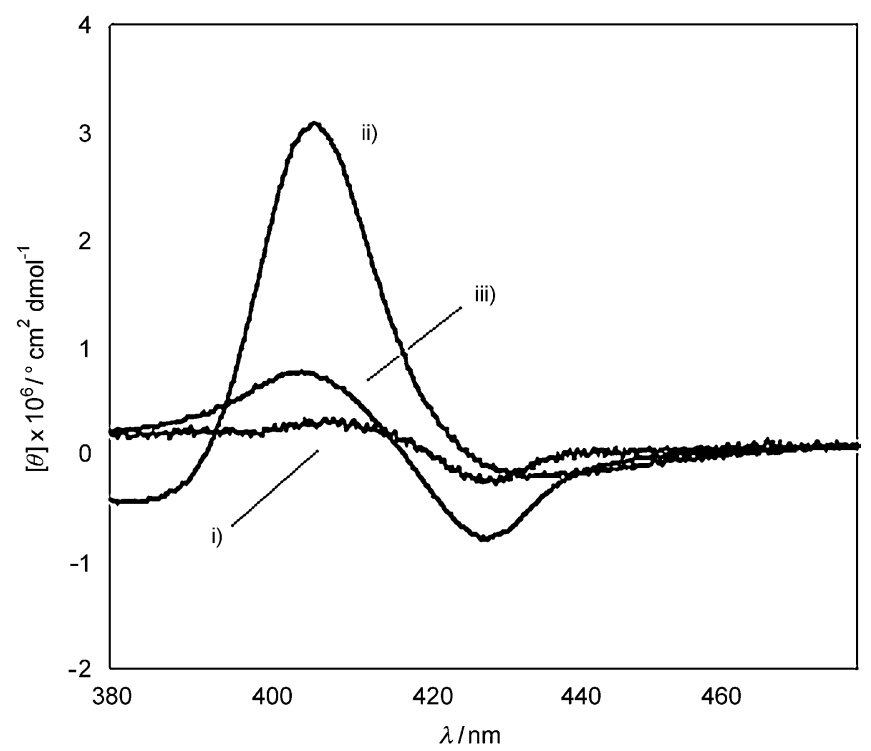

Figure 6. CD spectra of $\mathbf{H}_{2}$ DGS-P in DMA/water $(87: 13,298 \mathrm{~K})$ at different porphyrin concentrations: i) 0.8 , ii) 1.6 , iii) $2.4 \mu \mathrm{M}$.

Table 2. Kinetic parameters for aggregation of $\mathbf{H}_{2}$ TGS-P. ${ }^{[a]}$

\begin{tabular}{lll}
\hline$\left[\mathbf{H}_{\mathbf{2}}\right.$ TGS-P $][\mu \mathrm{M}]^{[\mathrm{a}]}$ & $k\left[\mathrm{~s}^{-1}\right]$ & $n$ \\
\hline 0.69 & $0.32 \pm 0.05$ & $0.81 \pm 0.01$ \\
1.33 & $1.08 \pm 0.04$ & $0.57 \pm 0.05$ \\
1.99 & $1.47 \pm 0.02$ & $0.81 \pm 0.02$ \\
2.66 & $2.00 \pm 0.03$ & $0.68 \pm 0.07$ \\
3.32 & $6.12 \pm 0.1$ & $0.40 \pm 0.02$ \\
\hline
\end{tabular}

[a] Runs carried out in DMAc/ $\mathrm{H}_{2} \mathrm{O}$ (91:9) at $298 \mathrm{~K}$. Kinetics monitored at $\lambda=413 \mathrm{~nm}$. Values were calculated by using Equation (2).

several orders of magnitude faster than that observed for disubstituted $\mathbf{H}_{2}$ DGS-P, owing to the increased hydrophobic character brought about by replacement of pentafluorophenyl moieties by steroid groups. This is also reflected in the aggregation profiles, which show diffusion-limited behaviour (DLA) throughout the explored concentration range (i.e., 0.7-3.3 $\mu \mathrm{M}$ ). Evidently, the increased hydrophobicity of the molecular frameworks fosters rapid aggregation of the macrocycles into a large number of small nucleation seeds, biasing the rate-limiting step to that of their further growth by diffusion-limited inclusion of residual monomers. The rate constant regularly increases with increasing initial porphyrin concentration up to $2.7 \mu \mathrm{M}$ (Table 2). Above this value an abrupt increase of the rate is observed (Figure 7), probably associated with formation of morphologically different species (i.e., $\mathrm{H}$ versus $\mathrm{J}$ aggregates), as already indicated by $\mathrm{UV} / \mathrm{Vis}$ and $\mathrm{CD}$ techniques.

AFM studies: Atomic force microscopy studies of the aggregates of $\mathbf{H}_{2}$ DGS-P and $\mathbf{H}_{\mathbf{2}}$ TGS-P were carried out on freshly cleaved graphite sheets (HOPG). The samples were prepared by drop casting (see Experimental Section) from aggregate solutions formed in DMAc/water of the same composition as used for the kinetic investigations. Reproducible 


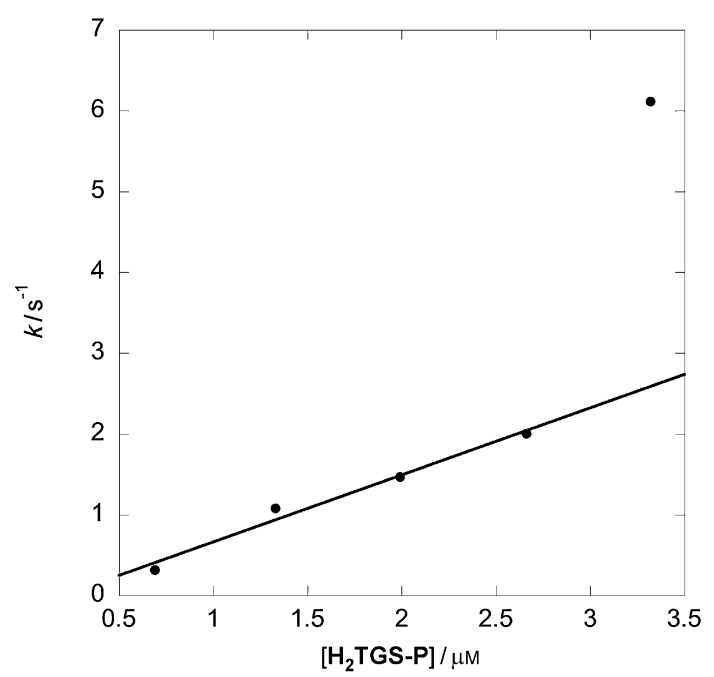

Figure 7. Plot of kinetic constants versus porphyrin concentration for the aggregation of $\mathbf{H}_{2}$ TGS-P in DMAc/ $\mathrm{H}_{2} \mathrm{O}$ (91:9). The point at higher concentration was omitted from the regression fit.

results, in terms of different batches and different regions scanned, were obtained. The same holds for topographies on glass surfaces, acquired by optical spectroscopy (see Experimental Section and ESI for details), which showed formation of very similar structures, ruling out the effect of the surface on the morphology of the aggregates. ${ }^{[34]}$

In particular, in the case of the aggregates of $\mathbf{H}_{2}$ DGS-P formed at lower concentration $(0.8 \mu \mathrm{M})$, the images show the presence of fibril structures, up to tens of micrometers in length and 300-500 nm wide (see Supporting Information, Figure S1), bundled in larger fibres (Figure 8, top left). At intermediate concentration (i.e., $1.6 \mu \mathrm{M}$, Figure 8, top right), the structures appear as wider $(350-550 \mathrm{~nm}$, see Supporting Information, Figure S2), mostly isolated rods, with a mean length of about $10 \mu \mathrm{m}$. Interestingly, the structures formed at higher concentration $(2.4 \mu \mathrm{M}$, at which a DLA mechanism is manifested) show a different morphology (Figure 8, lower left). In this case the porphyrin structures appear as aggregate rods $(10 \mu \mathrm{m}$ in length, $150-200 \mathrm{~nm}$ wide; see Supporting Information, Figure S3), which on closer inspection appeared to be the result of coalescence of smaller globular entities into longer fibril-like structures. A related issue was recently exploited by Liu et al, who demonstrated evolution of porphyrin globular nanostructures into nanofibers. ${ }^{[35]}$ The different morphologies of the aggregates are the consequence of the progressive change of mechanism, driven by changing concentration.

In the case of tetrasubstituted $\mathbf{H}_{2}$ TGS-P, which has the least CD active self-assembled structures, only aspecific randomly aggregated nanoparticle-like species are formed (Figure 8, lower right) with diameters of about $300-350 \mathrm{~nm}$ (estimated for isolated structures; see Supporting Information, Figure S4). The same result was found for structures formed at different concentrations. These results are consistent with some recent works, in which the structures of amphiphilic porphyrin nanoparticles, formed in good/poor sol-
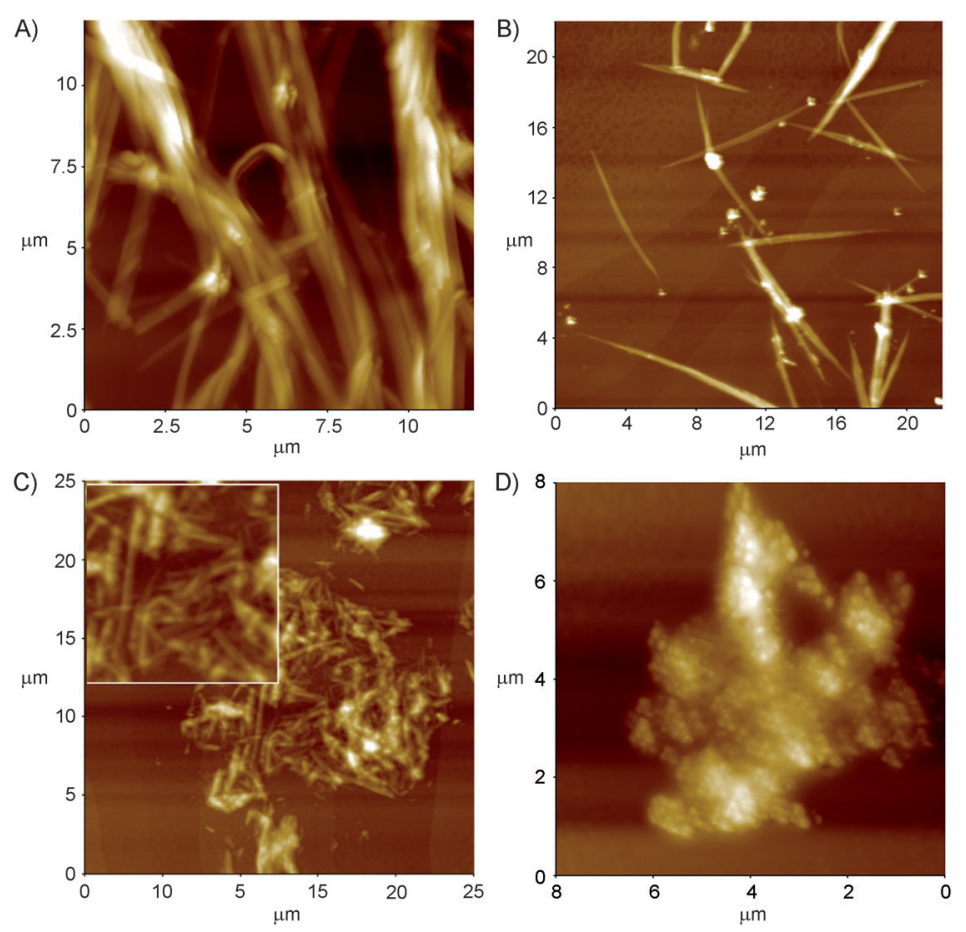

Figure 8. AFM topographies (HOPG) of aggregates of $\mathbf{H}_{2}$ DGS-P formed at different porphyrin concentrations (DMAc/ $\left.\mathrm{H}_{2} \mathrm{O}, 87: 13\right)$ : A) 0.8, B) 1.6, C) $2.4 \mu \mathrm{M}$ (inset: an enlargement of the central area). D) AFM image of H TGS-P aggregates (2.4 $\left.\mu \mathrm{M}, \mathrm{DMAc} / \mathrm{H}_{2} \mathrm{O}, 91: 9\right)$.

vent mixtures, were shown to be dependent on the monomer structures and on the conditions of formation. ${ }^{[36]}$

Besides, we serendipitously found that aggregates of porphyrin $\mathbf{H}_{2}$ DGS-P precipitated from solution $(0.8 \mu \mathrm{M}$ in $87: 13$ DMAc $/ \mathrm{H}_{2} \mathrm{O}$ ) upon standing overnight after their formation, to form a coagulated gel of brownish porphyrin material flocculated from the solution. These porphyrin macroaggregates are very stable, and remain unchanged in solution after months of storage. This is in close analogy to the results of Balaban and co-workers describing the formation of an artificial antenna system of photosynthetic bacteria (synthetic chlorosomes) in hydrocarbon solvents. ${ }^{[37]}$ The formation of such structures is due to the synergic presence of both cholesterol and sugar groups, which are known to be the key functionality for the achievement of self-assembled fibril structures and gels. ${ }^{[38]}$ SEM and conventional electron microscopy studies on this colloidal air-dried material layered on glass cover slides showed formation of fibres up to a millimetre in length (Supporting Information, Figure S6).

Computational studies: Semiempirical calculations were carried out with the aim of gaining information on the structures of the $\mathbf{H}_{2}$ DGS-P porphyrin aggregates, and on the driving force steering the specificity of the self-recognition process. We chose this compound as a model owing to the lower complexity of the structure and its more pronounced chiroptical properties. As, in a first instance, the nature of the sugar has no effect on the sign of the CD spectra of the 
aggregates, which is indicative of their helicity, the calculations were performed on the model compound $\mathbf{H}_{2}$ DGS-P, pruned of the sugar pendant groups. This protocol gave us the fundamental advantage of a reasonable calculation speed. All calculations were carried out with the PM6 method $^{[39]}$ as implemented in the program MOPAC 2009. ${ }^{[40]}$

A thorough conformational search around the four rotatable bonds of the steroid pendants of $\mathbf{H}_{2}$ DGS-P revealed that the most stable structure corresponds to the expected all-anti conformer (Supporting Information, Figure S6). Several starting geometries for optimization of an L-handed dimer of porphyrin $\mathbf{H}_{2}$ DGS-P (i.e., the anticlockwise $\Lambda$ isomer of $M$ helicity) were built by placing two monomers in their minimum-energy conformations close to each other in proper relative orientations. Interestingly, most of the starting geometries evolved into the same compact structure, which proved to be the most stable among all optimized geometries. The steroid pendants on different molecules are in close contact, and this suggests that van der Waals interactions between their surfaces play a major role in aggregate formation. Furthermore, some deviations from planarity, with a mean value of about $0.21 \AA$, are observed in the porphyrin rings (Supporting Information, Figure S8).

When the same study was performed on D-handed dimers (i.e. the clockwise $\Delta$ isomer, of $P$ helicity) again most starting geometries converged to a unique structure. In this case, minor deviations from planarity are observed in the porphyrin ring, and the steroid pendants of different monomers mutually interact (Supporting Information, Figure S9). The contact surface between these pendants is clearly smaller than in the related $\Lambda$ structure. Since all other structural features are almost identical in the two cases, it can be reasonably argued that such a looser interaction between the pendants should cause a lower stability of the $\Delta$ dimer, which indeed has been calculated to be about $37 \mathrm{~kJ} \mathrm{~mol}^{-1}$. To obtain a pictorial structure that well illustrates how in our opinion the above finding can explain the experimentally observed handedness, we built a porphyrin tetramer by placing two $\Lambda$ dimers one above the other (Supporting Information, Figure S10).

The steroid pendants were positioned in relative orientations that allow alternate interactions between the monomers, and the resulting geometry was subsequently optimized at the PM6 level by using the MOZYME function of MOPAC 2009 (Figure 9). This optimized geometry is a reasonable "short model" for porphyrin aggregates of $\mathbf{H}_{2}$ DGS$\mathbf{P}$ that shows, and corroborates, how the favourable van der Waals interactions between the steroid pendants, responsible for the highest stability of the L-handed dimer, and subsequently of its tetramer, should also govern the handedness of higher aggregates. We are aware that these "gas-phase" calculations overlook the role of the solvent, which always plays an important role in molecular recognition. However, the discriminating effect should be that of a "differential solvation" between the oppositely handed structures. The resulting overall effect in our opinion would be negligible, as the solvents considered in our studies are not chiral, and

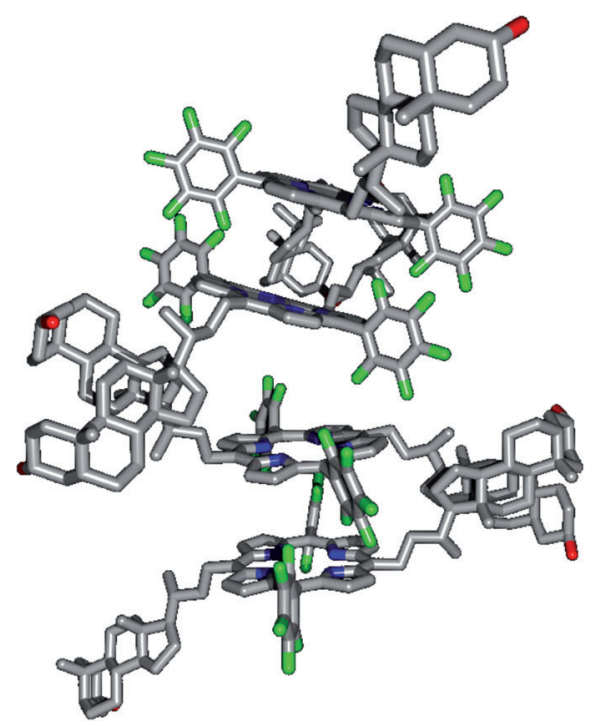

Figure 9. Representation of a tetramer of porphyrin $\mathbf{H}_{2}$ DGS-P in which the L-handedness is the result of favourable van der Waals interactions between the steroid pendant moieties.

should interact in a similar way with both of the differently handed growing suprastructures.

\section{Conclusion}

The aggregation properties of some elaborate porphyrin architectures, decorated with steroid linked to glucosidic moieties, have been studied in water/DMAc by different spectroscopic techniques, which revealed that aggregation leads to formation of species featuring supramolecular chirality. The results obtained indicate that it is possible to modulate the chirality of the overall supramolecular structures by changing the nature of the ancillary group present on the periphery of the porphyrin macrocycles, their concentration and the composition of the media. These experimental and molecular parameters also play a fundamental role in determining the overall morphology and the size of the aggregates. Moreover the experimental findings suggest that the intimate mutual arrangement of porphyrins, as well as their electronic coupling, is dictated by the chiral information stored on the linking steroid groups. In the case of the disubstituted $\mathbf{H}_{2}$ DGS-P derivative, semiempirical calculations gave a rationale for the experimental results. The complexity of the molecular structure of the investigated systems renders them amenable to further investigation in terms of molecular recognition properties, either in the solid state for the detection of complex volatile matrices, ${ }^{[4]}$ or in solution. ${ }^{[42]}$ The results presented should be of importance for the construction of sensor devices featuring stereoselective features ${ }^{[43]}$ or for obtaining solid-state materials with chiral properties, ${ }^{[4]}$ toward asymmetric catalysis. ${ }^{[45,15 \mathrm{~d}]}$ Studies devoted to exploiting the electrochemical behaviour of these interesting systems are underway. 


\section{Experimental Section}

General: Spectroscopic measurements were performed by using a Varian Cary 1E UV/Vis spectrophotometer at RT. Fluorescence and resonance light scattering studies were carried out by using FluoroMax-2 spectrofluorophotometers; concentrations used for $\mathrm{UV} / \mathrm{Vis}$ and fluorescence measurements were $(0.8-5.0) \times 10^{-6} \mathrm{~mol} \mathrm{~L}^{-1}$, unless otherwise indicated.

Aggregation studies: All spectroscopic studies were carried out at $298 \mathrm{~K}$, unless otherwise indicated. Solutions suitable for aggregation studies were prepared as follows: Appropriate aliquots of a stock solution in DMAc (15-150 $\mu \mathrm{L})$ were added to a suitable amount of solvent in a glass vial, then the solution was made up to $4.0 \mathrm{~mL}$ with water to give a solution with the desired water/organic solvent ratio and a range of porphyrin concentrations $\left(0.8-5.0 \mu \mathrm{mol} \mathrm{L}^{-1}\right)$, unless otherwise indicated. A sample $(\approx 3 \mathrm{~mL})$ was transferred to a quartz cuvette and relative UV/Vis spectra were acquired. The corresponding absorbance versus solvent composition (i.e., \% water) plots indicate the critical aggregation solvent composition at which aggregation occurs. Spectra were further acquired at different times to get indications of the proper solvent mixture for kinetic experiments.

Kinetic studies: Kinetic experiments were performed at $(298 \pm 0.5) \mathrm{K}$ by using a Varian Cary 1E spectrophotometer equipped with a thermostating apparatus, by measuring the UV/Vis spectroscopic changes (Soret B band) of porphyrin derivatives over time. Porphyrin aqueous solutions suited for kinetic studies were prepared as follows. Appropriate aliquots of a stock solution of porphyrin in DMAc $(15-150 \mu \mathrm{L})$ were added to a suitable amount of DMAc, then water was added to give an $87 \%$ DMAc/water solution with a final porphyrin concentration in the range of $0.8-2.4 \mu$ M. A suitable portion $(\approx 2.5 \mathrm{~mL})$ was rapidly transferred to a quartz or optical-glass cuvette, and relative UV/Vis spectra acquired over time. In the case of faster reactions (higher porphyrin concentrations), the solutions were prepared directly in the measurement cuvette. The stock solutions were always pretreated by filtration through nylon syringe filters (Albet, $0.45 \mu \mathrm{m}$ diameter) and used within a week of preparation. Values of $k$ were obtained by analysing the absorbance (extinction) versus time data points by the above equations (see text). The kinetic parameters were obtained by nonlinear least-squares regression fit (Kaleidagraph program, Synergy Software, 2003) over hundreds of experimental data points. The quality of the fits is generally very good, with $R^{2} \geq$ 0.9994. For faster reactions, the "zero-time" input values were calculated by measuring the B-band absorbance under non-aggregative conditions (i.e., solutions with higher DMAc contents closer to that employed for kinetic experiments). The nonlinear regressions were run accordingly to give the other kinetic parameters with the smallest calculated errors. Final regressions were then made with "free" zero-time parameters, and the calculated values for Ext ${ }_{\infty}$ and Ext ${ }_{0}$ were found to be always in excellent agreement with the experimental values. Data reported are the average values of at least two different runs with uncertainties within $5 \%$.

Atomic force microscopy: AFM topographic studies were carried out by using a PSIA-XE 100 instrument. Experiments were carried out in nocontact mode on freshly cleaved highly oriented pyrolytic graphite (HOPG; TAAB Laboratories Equipment, UK) by using PSIA-NCHR probes with a resonant frequency of $320 \mathrm{kHz}$ and a force constant of $42 \mathrm{~N} \mathrm{~m}^{-1}$. The no-contact mode was used because the alternative contactmode procedure resulted in disaggregation of the aggregates. Samples were prepared by drop casting of DMAc/water solutions of porphyrin aggregates onto HOPG. The aggregates were formed in the solvent composition used for kinetic experiments at micromolar concentrations, unless otherwise indicated. A drop of solution was brought into contact with a freshly cleaved HOPG surface for 1-10 min. Excess solution was absorbed with filter paper, then the sample was dried with a nitrogen stream.

Optical microscopy: Optical micrographs were obtained by using a Leica DM 2500M instrument. Samples were prepared by drop casting of DMAc/water aggregate solutions onto microscope cover glass (Thermo Scientific; Erie Scientific Company, USA). The glass slips were cleaned by immersion into freshly prepared alkaline piranha solution $(30 \%$ hydrogen peroxide/aqueous ammonia solution 1:3, Caution!) for $30 \mathrm{~min}$ at
RT, thoroughly rinsed with Milli-Q (Millipore) distilled water, then dried with an ultrapure nitrogen stream.

Circular dichroism spectroscopy: $\mathrm{CD}$ spectra were recorded by using a JASCO J-600 spectrometer equipped with a thermostated cell holder at $298 \mathrm{~K}$, and purged with ultrapure nitrogen gas. The samples were prepared by following the procedure described for the UV/Vis and kinetic studies.

Resonance light scattering: RLS experiments were performed by using a FluoroMax-2 spectrofluorophotometer. Spectra were acquired at (298 \pm $0.5) \mathrm{K}$ in a "synchronous scan" mode, in which the emission and excitation monochromators were preset to identical wavelengths. Solutions were prepared by following the protocol used in the UV/Vis aggregation studies.

Fluorescence spectroscopy experiments: Fluorescence spectra were recorded at $(298 \pm 0.5) \mathrm{K}$ by using a JASCO 780 or a FluoroMax-2 spectrofluorophotometer. Solutions were prepared by following the protocol used in the UV/Vis aggregation studies. Excitation wavelengths correspond to that of the most intense Q-band maxima.

\section{Acknowledgements}

This work was supported by NATO (grant CBP.EAP.CLG.982972) and by the Ministry of Education, Youth and Sports of the Czech Republic (project nos. MSM6046137305, 2B06024 SUPRAFYT). We also thank MiUR-PRIN, Italy (project no. 20088NTBKR; 2008) for partial financial support. The helpful discussion of Profs. Gianfranco Ercolani and Roberto Paolesse (University of Rome, Tor Vergata) is gratefully acknowledged. We also wish to thank Dr. A. D'Epifanio (University of Rome, Tor Vergata) for SEM studies.

[1] a) Topics in Current Chemistry, Vol.265, Supramolecular Chirality (Eds.: M. Crego-Calama, D. N. Reinhoudt), Springer, Berlin, 2006; b) M. A. Mateos-Timoneda, M. Crego-Calama, D. N. Reinhoudt, Chem. Soc. Rev. 2004, 33, 363-372; c) A. R. A. Palmans, E. W. Meijer, Angew. Chem. 2007, 119, 9106-9126; Angew. Chem. Int. Ed. 2007, 46, 8948-8968.

[2] a) I. Occhiuto, G. De Luca, V. Villari, A. Romeo, N. Micali, R. F. Pasternack, L. Monsù Scolaro, Chem. Commun. 2011, 47, 60456047; b) R. F. Pasternack, E. J. Gibbs, D. Bruzewicz, D. Stewart, K. Shannon Engstrom, J. Am. Chem. Soc. 2002, 124, 3533-3539; c) J. Parkash, J. H. Robblee, J. Agnew, E. Gibbs, P. Collings, R. F. Pasternack, J. C. de Paula, Biophys. J. 1998, 74, 2089-2099; d) M. Balaz, M. De Napoli, A. E. Holmes, A. Mammana, K. Nakanishi, N. Berova, R. Purrello, Angew. Chem. 2005, 117, 4074-4077; Angew. Chem. Int. Ed. 2005, 44, 4006-4009; e) For "template-imprinted" chiral suprastructures and remarkable examples of "chiral memory", see: R. Purrello, A. Raudino, L. Monsù Scolaro, A. Loisi, E. Bellacchio, R. Lauceri, J. Phys. Chem. B 2000, 104, 10900-10908; Scolaro, A. Loisi, E. Bellacchio, R. Lauceri, J. Phys. Chem. B 2000, 104, 10900-10908; f) E. Bellacchio, R. Lauceri, S. Guerrieri, L. Monsù Scolaro, A. Romeo, R. Purrello, J. Am. Chem. Soc. 1998, 120, 12353-12354; g) A. Mammana, A. D'Urso, R. Lauceri, R. Purrello, J. Am. Chem. Soc. 2007, 129, 8062-8063; h) G. De Luca, A. Romeo, L. Monsù Scolaro, R. F. Pasternack, Chem. Commun. 2010, 46, 389391.

[3] a) Y. Kubo, Y. Ishii, T. Yoshizawa, S. Tokita, Chem. Commun. 2004, 1394-1395; b) D. Monti, L. La Monica, A. Scipioni, G. Mancini, New J. Chem. 2001, 25, 780-782; c) V. V. Borovkov, T. Harada, G. A. Hembury, Y. Inoue, R. Kuroda, Angew. Chem. 2003, 115, 1788-1791; Angew. Chem. Int. Ed. 2003, 42, 1746-1749; d) G. Pescitelli, S. Gabriel, Y. Wang, J. Fleischhauer, R. W. Woody, N. Berova, J. Am. Chem. Soc. 2003, 125, 7613-7628, and references therein.

[4] a) J. M. Ribó, J. Crusats, F. Sagués, J. Claret, R. Rubires, Science 2001, 292, 2063-2066; b) R. Rubires, J.-A. Farrera J. M. Ribó, Chem. Eur. J. 2001, 7, 436-446; c) A. Tsuda, Md. A. Alam, T. 
Harada, T. Yamaguchi, N. Ishii, T. Aida, Angew. Chem. 2007, 119, 8346-8350; Angew. Chem. Int. Ed. 2007, 46, 8198-8202; d) T. Yamaguchi, T. Kimura, H. Matsuda, T. Aida, Angew. Chem. 2004, 116, 6510-6515; Angew. Chem. Int. Ed. 2004, 43, 6350-6355.

[5] L. Zeng, Y. He, Z. Dai, J. Wang, Q. Cao, Y. Zhang, ChemPhysChem 2009, 10, 954-962.

[6] a) Y. Zhang, P. Chen, M. Liu, Chem. Eur. J. 2008, 14, 1793-1803; b) P. Chen, X. Ma, P. Duan, M. Liu, ChemPhysChem 2006, 7, 24192423 ; c) Y. Qiu, P. Chen, M. Liu, Langmuir 2010, 26, 15272-15277.

[7] Z. El-Hachemi, G. Mancini, J. M. Ribó, A. Sorrenti, J. Am. Chem. Soc. 2008, 130, 15176-15184.

[8] a) D. Monti, M. De Rossi, A. Sorrenti, G. Laguzzi, E. Gatto, M. Stefanelli, M. Venanzi, L. Luvidi, G. Mancini, R. Paolesse, Chem. Eur. J. 2010, 16, 860-870; b) D. Monti, M. Venanzi, M. Stefanelli, A. Sorrenti, G. Mancini, C. Di Natale, R. Paolesse, J. Am. Chem. Soc. 2007, 129, 6688-6689; c) D. Monti, M. Venanzi, G. Mancini, C. Di Natale, R. Paolesse, Chem. Commun. 2005, 2471-2473; d) D. Monti, V. Cantonetti, M. Venanzi, F. Ceccacci, C. Bombelli, G. Mancini, Chem. Commun. 2004, 972-973. Studies on the aggregation of related chiral porphyrin derivatives have been recently reported by others. See, for example: e) P. Iavicoli, M. Simón-Sorbed, D. B. Amabilino, New J. Chem. 2009, 33, 358-365; f) P. Iavicoli, H. Xu, L. N. Feldborg, M. Linares, S. Stafsrtöm, C. Ocal, B. Nieto-Ortega, J. Casado, J. T. López Navarrete, R. Lazzaroni, S. De Feyter, D. B. Amabilino, J. Am. Chem. Soc. 2010, 132, 9350-9362. Porphyrin-substituted nucleotides have been recently reported to successfully implement into helical DNA scaffolds: g) I. Bouamaied, T. N. Nguyen, T. Rühl, E. Stulz, Org. Biomol. Chem. 2008, 6, 3888-3891.

[9] a) P. Štěpánek, M. Dukh, D. Šaman, J. Moravcová, L. Kniežo, D. Monti, M. Venanzi, G. Mancini, P. Drašar, Org. Biomol. Chem. 2007, 5, 960-970; b) D. Monti, E. Gatto, M. Venanzi, G. Mancini, A. Sorrenti, P. Štěpánek, P. Drašar, New J. Chem. 2008, 32, $2127-$ 2133. For other related studies, see: c) C. Schell, H. K. Hombrecher, Chem. Eur. J. 1999, 5, 587-598; d) M. Dukh, P. Drašar, I. Černý, V. Pouzar, J. A. Shriver, J. L. Sessler, Supramol. Chem. 2002, 14, $237-$ 244; e) M. Dukh, D. Šaman, J. Kroulík, I. Černý, V. Pouzar, V. Král, P. Drašar, Tetrahedron 2003, 59, 4069-4076; f) N. T. T. Huong, P. Klímková, A. Sorrenti, G. Mancini, P. Drašar, Steroids 2009, 74, 715-720; g) P. Štěpánek, O. Šimák, Z. Novákova, Z. Wimmer, P. Drašar, Org. Biomol. Chem. 2011, 9, 682-683.

[10] a) R. Fong, D. I. Schuster, S. R. Wilson, Org. Lett. 1999, 1, 729-732; b) T. S. Balaban, N. Berova, C. M. Drain, R. Hauschild, X. Huang, H. Kalt, S. Lebedkin, J.-M. Lehn, F. Nifaitis, G. Pescitelli, V. I. Prokhorenko, G. Riedel, G. Smeureanu, J. Zeller, Chem. Eur. J. 2007, $13,8411-8427$

[11] a) S.-H. Chen, H. Zhu, B. Liu, H. Zhao, Youji Huaxue 1988, 8, 3436; b) S.-H. Chen, Y. Chen, H.-G. Li, Ниахие Хuebao 1997, 44, $716-722$.

[12] M. Dukh, D. Šaman, K. Lang, V. Pouzar, I. Černý, P. Drašar, V. Král, Org. Biomol. Chem. 2003, 1, 3458-3463.

[13] E. Girgenti, R. Ricoux, J.-P. Mahy, Tetrahedron 2004, 60, 1004910058.

[14] Y. Li, J. R. Dias, Chem. Rev. 1997, 97, 283-304.

[15] a) J. T. Groves, R. Neumann, J. Am. Chem. Soc. 1989, 111, 29002909; b) J. Lahiri, G. D. Fate, S. B. Ungashe, J. T. Groves, J. Am. Chem. Soc. 1996, 118, 2347-2358; c) For other examples of P450 mimics see, for example: D. Monti, P. Tagliatesta, G. Mancini, T. Boschi, Angew. Chem. 1998, 110, 1154-1156; Angew. Chem. Int. Ed. Engl. 1998, 37, 1131-1133; d) S. Borocci, F. Marotti, G. Mancini, D. Monti, A. Pastorini, Langmuir 2001, 17, 7198-7203; e) V. Cantonetti, D. Monti, M. Venanzi, C. Bombelli, F. Ceccacci, G. Mancini, Tetrahedron: Asymmetry 2004, 15, 1969-1977.

[16] a) L. G. Mackay, R. P. Bonar-Law, J. K. M. Sanders, J. Chem. Soc. Perkin Trans. 1 1993, 1377-1378; b) R. P. Bonar-Law, L. G. Mackay, J. K. M. Sanders, J. Chem. Soc. Chem. Commun. 1993, 456-458; c) R. P. Bonar-Law, J. K. M. Sanders, J. Chem. Soc. Perkin Trans. 1 1995, 3085-3096; d) R. P. Bonar-Law, J. K. M. Sanders, J. Chem. Soc. Chem. Commun. 1991, 574-577.
[17] It has been recently demonstrated that porphyrin-steroid conjugates self-assemble into nanoparticle structures featuring interesting properties as molecular receptors for nitrogen-based organic ligands or organic mercury in water: a) S. Tomas, L. Milanesi, J. Am. Chem. Soc. 2009, 131, 6618-6623; b) B.-W. Liu, Y. Chen, B.-E. Song, Y. Liu, Chem. Commun. 2011, 47, 4418-4420; c) For a recent overview on the application of porphyrin derivatives in chemical sensors, see: R. Paolesse, D. Monti, S. Nardis, C. Di Natale in The Handbook of Porphyrin Science, Vol. 12 (Eds.: K. M. Kadish, K. M. Smith, R. Guilard), World Scientific, London, 2010, Chapter 54, pp. 121-226 .

[18] a) M.-C. Desroches, A. Kasselouri, M. Meyniel, P. Fontaine, M. Goldmann, P. Prognon, P. Maillard, V. Rosilio, Langmuir 2004, 20 , 11698-11705; b) A. Lavi, H. Weitman, R. T. Holmes, K. M. Smith, B. Ehrenberg, Biophys. J. 2002, 82, 2101-2110; c) S. Ferro, F. Ricchelli, D. Monti, G. Mancini, G. Jori, Int. J. Biochem. Cell Biol. 2007, 39, 1026-1034; d) For an overview on the application of porphyrin derivatives as therapeutic agents, see: R. K. Pandey, G. Zheng in The Porphyrin Handbook, Vol. 6 (Eds.: K. M. Kadish, K. M. Smith, R. Guilard), Academic, New York, 2000, Chapter 43, pp. $157-230$.

[19] K. Zelenka, T. Trnka, I. Tišlerová, V Král. M. Dukh, P. Drašar, Coll. Czech. Chem. Commun. 2004, 69, 1149-1160.

[20] R. F. Pasternack, P. J. Collings, Science 1995, 269, 935-939.

[21] a) S. Allenmark, Chirality 2003, 15, 409-422, and references therein; b) Formation of chiral supramolecular systems as a consequence of interaction of achiral dendritic macromolecules with chiral ionic cholesteric groups was recently reported: A. J. Soininen, E. Kasëmi, A. D. Schlüter, O. Ikkala, J. Ruokolainen, R. Mezzenga, J. Am. Chem. Soc. 2010, 132, 10882-10890.

[22] a) F. Helmich, C. C. Lee, M. M. L. Niewenhuizen, J. C. Gielen, P. C. M. Christianen, A. Larsen, G. Fytas, P. E. L. G. Leclere, A. P. H. J. Schenning, E. W. Meijer, Angew. Chem. 2010, 122, 40314034; Angew. Chem. Int. Ed. 2010, 49, 3939-3942; b) G. De Luca, A. Romeo, V. Villari, N. Micali, I. Foltran, E. Foresti, I. G. Lesci, N. Roveri, T. Zuccheri, L. Monsù Scolaro, J. Am. Chem. Soc. 2009, 131, 6920-6921; c) N. C. Maiti, S. Mazumdar, N. Periasamy, J. Porphyrins Phthalocyanines 1998, 2, 369-376.

[23] X. W. Li, D. J. Li, W. F. Zeng, G. L. Zou, Z. P. Chen, J. Phys. Chem. $B$ 2007, 111, 1502-1506.

[24] V. V. Borovkov, G. A. Hembury, Y. Inoue, Acc. Chem. Res. 2004, 37, 449-459.

[25] N. Berova, K. Nakanishi in Circular Dichroism. Principles and Applications, 2nd ed. (Eds.: N. Berova, K. Nakanishi, R. W. Woody), Wiley, New York, 2000. p. 337-382.

[26] DMAc is quite a strong hydrogen-bond acceptor solvent. We could not find direct data on the hydrogen-bond accepting capability (Kamlet-Taft parameter $\beta$ ) for DMAc, but we can safely assume that it should be similar to that of the closely structurally related $N, N$-dimethylformamide (DMF), which is $\beta=0.69$. We made this assumption on the basis of the similarity of their Dimroth solvent parameters, which are $E_{\mathrm{T}}(30)=43.2$ and 42.9 for DMF and DMAc, respectively, and on the basis of the Abraham's $K_{\mathrm{B}}^{\mathrm{H}}$ values, which for a series of alkyl amides are all similar and around 0.70: a) C. Reichardt, Solvents and Solvents Effects in Organic Chemistry, 3rd ed. Wiley-VCH, Weinheim, 2004 ; b) M. H. Abraham, P. L. Grellier, D. V. Prior, J. J. Morris, P. J. Taylor, J. Chem. Soc. Perkin Trans. 2 1990, $521-529$.

[27] R. F. Pasternack, E. J. Gibbs, P. J. Collings, J. C. dePaula, L. C. Turzo, A. Terracina, J. Am. Chem. Soc. 1998, 120, 5873-5878.

[28] The term extinction is more appropriate than absorbance, because of the presence of RLS scattering contribution to UV/Vis bands. See, for example, N. Micali, F. Mallamace, M. Castriciano, A Romeo, L. Monsú Scolaro, Anal. Chem. 2001, 73, 4958-4963.

[29] A different interpretation of the meaning of the parameter $m$ has been offered by others, for the formation of small aggregates of benzoporphyrin derivatives (DiesterB) in aqueous solvent mixtures. It was proposed that this value accounts not only for the nucleus size, but also for their quantity formed in the first lag period: F. I. Simpli- 
cio, R. Ribeiro da Silva Soares, F. Maionchi, O. S. Filho, N. Hioka, J. Phys. Chem. A 2004, 108, 9384-9389.

[30] a) R. F. Pasternack, C. Fleming, S. Herring, P. J. Collings, J. C. dePaula, J. DeCastro, E. J. Gibbs, Biophys. J. 2000, 79, 550-560; b) M. A. Castriciano, A. Romeo, L. Monsù Scolaro, J. Porphyrins Phthalocyanines 2002, 6, 431-438.

[31] L. Monsù Scolaro, M. A. Castriciano, A. Romeo, A. Mazzaglia, F. Mallamace, N. Micali, Physica A 2002, 304, 158-169.

[32] N. Micali, V. Villari, M. A. Castriciano, A. Romeo, L. Monsù Scolaro, J. Phys. Chem. B 2006, 110, 8289-8295.

[33] The deposition surface may affect the morphology of layered assemblies of porphyrins. Recent examples: a) P. Donovan, A. Robin, M. S. Dyer, M. Perrson, R. Raval, Chem. Eur. J. 2010, 16, 1164111652 ; b) M. Koepf, J. A. Wytko, J.-P. Bucher, J. Weiss, J. Am. Chem. Soc. 2008, 130, 9994-10001; c) M. Scarselli, G. Ercolani, P. Castrucci, D. Monti, G. Bussetti, M. Russo, C. Goletti, P. Chiaradia, R. Paolesse, M. De Crescenzi, Surf. Sci. 2007, 601, 2607-2610, and references therein. This is found, however, mostly for "bare" aryl porphyrins; in the case of supramolecular species held by more complex intermolecular interactions, the effect of the surface is less relevant. See, for example: d) A. D. Schwab, D. E. Smith, C. S. Rich, E. R. Young, W. F. Smith, J. C. de Paula, J. Phys. Chem. B 2003, 107, 11339-11345; e) J. A. A. W. Elemans, R. van Hameren, R. J. M. Nolte, A. E. Rowan, Adv. Mater. 2006, 18, 1251-1266; f) J. Otsuki, E. Nagamine, T. Kondo, K. Iwasaki, M. Asakawa, K. Miyake, J. Am. Chem. Soc. 2005, 127, 10400-10405.

[34] a) Y. Qiu, P. Chen, M. Liu, J. Am. Chem. Soc. 2010, 132, 9644-9652. The process of fibrillogenesis is of importance in investigations of the mechanism of formation of amyloid structures. See, for example: b) D. M. Walsh, A. Lomakin, G. B. Benedek, M. M. Condron, D. B. Teplow, J. Biol. Chem. 1997, 272, 22364-22372; c) I. W. Hamley, Angew. Chem. 2007, 119, 8274-8295; Angew. Chem. Int. Ed. 2007, 46, 8128-8147, and references therein.

[35] a) X. Gong, T. Milic, C. Xu, J. D. Batteas, C. M. Drain, J. Am. Chem. Soc. 2002, 124, 14290-14291; b) C. M. Drain, G. Smeureanu, S. Patel, X. Gong, J. Garno, J. Arijeloye, New J. Chem. 2006, 30, 1834-1843; c) G. Smeureanu, A. Aggarwal, C. E. Soll, J. Arijeloye, E. Malave, C. M. Drain, Chem. Eur. J. 2009, 15, 12133-12140.

[36] a) T. S. Balaban, A. D. Bhise, M. Fisher, M. Linke-Schaetzel, C. Roussel, N. Vanthuyne, Angew. Chem. 2003, 115, 2190-2194; Angew. Chem. Int. Ed. 2003, 42, 2140-2144; b) T. S. Balaban, M. Linke-Schaetzel, A. D. Bhise, N. Vanthuyne, C. Roussel, Eur. J. Org.
Chem. 2004, 3919-3930; c) T. S. Balaban, Acc. Chem. Res. 2005, 38, 612-623.

[37] a) J. Wu, T. Yi, Y. Zou, F. Liu, J. Dong, T. Shu, F. Li, C. Huang, Chem. Eur. J. 2009, 15, 6234-6243; b) J. H. Jung, S.-H. Lee, J. S. Yoo, K. Yoshida, T. Shimizu, S. Shinkai, Chem. Eur. J. 2003, 9, 5307-5313; c) O. Gronwald, S. Shinkai, Chem. Eur. J. 2001, 7, 43284334; d) M. Numata, S. Shinkai, Chem. Commun. 2011, 47, 19611975.

[38] J. J. P. Stewart, J. Mol. Model. 2007, 13, 1173-1213.

[39] J. J. P. Stewart, MOPAC2009, Stewart Computational Chemistry, Colorado Springs, CO, USA, 2008, http://OpenMOPAC.net.

[40] a) D. Filippini, A. Alimelli, C. Di Natale, R. Paolesse, A. D'Amico, I. Lundström, Angew. Chem. 2006, 118, 3884-3887; Angew. Chem Int. Ed. 2006, 45, 3800-3803; b) D. Filippini, C. Di Natale, R. Paolesse, A. D'Amico, I. Lundstrom, Sens. Actuators B 2007, 121, $93-$ 102 ; c) R. Paolesse, F. Mandoj, A. Marini, C. Di Natale in Encyclopedia of Nanoscience and Nanotechnology, Vol. 9 (Ed.: H. Nalwa), American Science, Valencia CA (USA), 2004, p. 21.

[41] L. Lvova, E. Martinelli, E. Mazzone, A. Pede, R. Paolesse, C. Di Natale, A. D'Amico, Talanta 2006, 70, 833-839.

[42] a) R. Paolesse, D. Monti, L. La Monica, M. Venanzi, A. Froiio, S Nardis, C. Di Natale, E. Martinelli, A. D'Amico, Chem. Eur. J. 2002 8, 2476-2483; b) R. Purrello, S. Guerrieri, R. Lauceri, Coord. Chem Rev. 1999, 190-192, 683-706; c) L. S. Dolci, E. Marzocchi, M. Montalti, L. Prodi, D. Monti, C. Di Natale, A. D'Amico, R. Paolesse, Biosens. Bioelectron. 2006, 22, 399-404; d) Y. Miura, T. Yamauchi, H. Sato, T. Fukuda, Thin Solid Films 2008, 516, 2443-2449; e) M Trojanowicz, M. Kaniewska, Electroanalysis 2009, 21, 229-238; f) For a review on chirality-sensing supramolecular systems, see: G. A. Hembury, V. V. Borovkov, Y. Inoue, Chem. Rev. 2008, 108, 1 73.

[43] Organogel systems based on porphyrin-sugar conjugates were shown to be suitable for the construction of chiral inorganic materials: S.-I. Kawano, S.-I. Tamaru, N. Fujita, S. Shinkai, Chem. Eur. J. 2004, 10, 343-351.

[44] a) T. Mallat, E. Orglmeister, A. Baiker, Chem. Rev. 2007, 107, 4863 4890; b) C. Li, H. Zhang, D. Jiang, Q. Yang, Chem. Commun. 2007, $547-558$.

[45] A. Rumlerova-Lipsová, J. Barek, P. Drasar, K. Zelenka, K. Pecková, Int. J. Electrochem. Sci. 2007, 2, 235-247, and references therein.

Received: April 15, 2011 Published online: November 3, 2011 